\title{
Peranan Orang Tua Dalam Pembentukan Spiritualitas Anak Umur 6-8 Tahun Di Gereja Kemah Injil Indonesia Jemaat Sei Barang Kalimantan Utara
}

\author{
Lawai Ula, Buce Zeth Tuhumury
}

\begin{abstract}
Abstrak
Orang tua sangat memegang peranan yang penting dalam hal pembentukan spiritualitas seorang anak. Peneliti telah melakukan penelitian dengan mengacu kepada keempat peranan orang tua dalam pembentukan spiritualitas anak yaitu mengajar anak untuk mengenal Alkitab, mengajar anak berdoa, membawa anak beribadah kepada Tuhan, dan mendorong anak untuk selalu memuji Tuhan. Hasil dari penelitian tersebut adalah bahwa dari 6 responden, hanya 1 orang $(16,67 \%)$ orang yang selalu mengajar anak untuk mengenal Alkitab. Dalam hal mengajar anak untuk berdoa, orang tua yang sering mengajar anak untuk berdoa juga hanya sekitar 1 orang $(16,67 \%)$. Untuk membawa anak beribadah kepada Tuhan terdapat 5 orang $(83,33 \%)$ orang tua yang selalu melakukan hal ini, dan hanya 1 orang $(16,67 \%)$ orang tua yang selalu mendorong anaknya untuk memuji Tuhan. Kesimpulan bahwa jika orang tua aktif mengajar anak untuk mengenal Alkitab, mengajar anak berdoa, membawa anak beribadah kepada Tuhan, dan mendorong anak untuk selalu memuji Tuhan, maka spiritualitas anak akan terbentuk dengan baik. Namun sebaliknya, jika orang tua tidak aktif mengajar anak untuk mengenal firman Tuhan atau Alkitab, mengajar anak berdoa, membawa anak beribadah kepada Tuhan, dan mendorong anak untuk selalu memuji Tuhan, maka spiritualitas anak tidak akan terbentuk dengan baik.
\end{abstract}

Kata Kunci: Peranan, Orang tua, Spiritualitas, Anak

\section{Pendahuluan}

\section{Latar Belakang Masalah}

Ayah dan Ibu disebut sebagai orang tua karena di tengah kedua-duanya ada anak yang dikaruniakan oleh Allah. Menurut "Ruth Nauli Aninda, "Anak adalah sebuah permata dan anugerah yang terindah dari Tuhan Yang Maha Esa." Berarti anak adalah sebuah pemberian dari Tuhan kepada kedua orang tua. Sejak anak lahir di tengah sebuah keluarga, saat itu pula kedua pasangan suami istri berstatus sebagai orang tua.

Seiring dengan perkembangan dunia zaman sekarang, kebutuhan hidup pun semakin meningkat, sehingga tidak heran orang tua terlalu sibuk dengan berbagai urusan atau

\footnotetext{
${ }^{1}$ Ruth Nauli Aninda, "Nilai Anak Perempuan Pada Keluarga Batak Ditinjau Dari Ibu Dewasa Awal Dan Dewasa Madya," Jurnal: Ilmiah Mahasiswa Universitas Surabaya 2, no. 1 (Maret 2013):2, diakses 4 September 2017, http://download.portalgaruda.org/article.php?article=119277\&val=5455.
} 
pekerjaan yang berkaitan dengan kebutuhan hidup dan akhirnya orang tua selalu menghabiskan waktu di tempat kerja, sedangkan waktu orang tua bersama dengan anak-anak di rumah sangat kurang. Hal tersebut tidak dapat dipungkiri, karena pada kenyataannya dalam dunia nyata, itulah yang terjadi. Hal ini senada juga dengan tulisan Myles Munreo dan David Burows, "Sering orang tua lebih banyak menghabiskan waktu di tempat kerjanya atau di jalan dari pada di rumah sehubungan dengan kebutuhan-kebutuhan hidup." 2 Jadi, pada intinya, bahwa orang tua zaman sekarang terlalu banyak sibuk dengan berbagai-bagai hal, sehingga secara tidak sadar orang tua kebanyakan menghabiskan waktu-waktunya hanya untuk kebutuhan hidup sehari-hari.

Hal yang sama pula terjadi di jemaat Sei Barang yaitu orang tua selalu menghabiskan waktunya di tempat pekerjaan sehingga orang tua kurang bersama anak-anaknya di rumah karena pada faktanya yang menjadi rutinitas utama orang tua ialah berladang, dan hanya sebagian kecil orang tua berstatus PNS (Pegawai Negeri Sipil). Setiap jam kerja, orang tua dengan sendirinya masing-masing beraktifitas sesuai dengan profesinya, yang pegawai bertugas sebagai pengajar dan yang petani juga setiap hari melalukan pekerjaannya sebagai pekerja ladang. Tanggung jawab yang telah kerjakan oleh setiap orang tua dapat diapresiasikan bahwa telah nyata orang tua memiliki semangat yang tinggi untuk memikul dan menanggung bebannya dalam mengusahakan segala nafkah hidup sehingga kebutuhan dan keperluan jasmani seisi rumahnya pun terpenuhi. Hal tersebut diketahui oleh peneliti selama menjadi anggota jemaat setempat.

Menurut Marjorie L. Thompson "Pembentukan rohani bukan sekadar pilihan yang boleh dipilih, dan boleh juga tidak. Pembentukan rohani anak adalah suatu kenyataan hidup yang utama."3 Artinya bahwa orang tua mutlak bertanggung jawab dalam membentuk spiritualitas anak-anaknya karena membentuk spiritualitas anak-anak oleh orang tua tidak boleh diabaikan melainkan orang tua harus menganggapnya sebagai yang paling utama

\section{Pokok Masalah}

Berdasarkan masalah yang telah diuraikan, yang menjadi pokok masalah dalam penulisan ini ialah sejauh mana "Peranan Orang Tua dalam Pembentukan Spiritualitas Anak Umur 6-8 Tahun di Gereja Kemah Injil Indonesia Jemaat Sei Barang Kalimantan Utara?”

\section{Tujuan Penelitian}

Akhir dari penulisan ini bertujuan untuk menemukan sejauh mana peranan orang tua dalam membentuk spiritualitas anak umur 6-8 tahun di Gereja Kemah Injil Indonesia Jemaat Sei Barang Kalimantan Utara.

\section{Manfaat Penelitian}

Adapun manfaat penulisan adalah:

${ }^{2}$ Myles Munreo, David Burows, Kingdom Parenting (Jakarta: Imanuel, 2002), 90.

${ }^{3}$ Marjorie L. Thompson, Keluarga Pusat Pembentukan Rohani (Jakarta: BPK Gunung Mulia, 2011), 10. 
Pertama, sebagai upaya meningkatkan pengetahuan tentang bagaimana mengamati masalah dan menuangkannya ke dalam skripsi.

Kedua, bagi orang tua, memotivasi orang tua agar bertanggung jawab membentuk spiritualitas anak umur 6-8 tahun di Gereja Kemah Injil Indonesia Jemaat Sei Barang Kalimantan Utara.

Ketiga, orang tua mendapat gambaran tentang peranannya dalam pembentukan spiritualitas anak umur 6-8 tahun di Gereja Kemah Injil Indonesia Jemaat Sei Barang Kalimantan Utara.

\section{Metode Penelitian} berikut:

Dalam penulisan ini, metode penelitian yang digunakan adalah kuantitatif sebagai

Pertama, tinjauan kepustakaan yaitu menganalisis secara teoritis data-data melalui buku-buku yang ada hubungan dengan judul skripsi ini.

Kedua, wawancara orang tua yang dianggap dapat memberi jawaban yang benar serta jujur terhadap pertanyan-pertanyaan sehubungan dengan pembahasan pada judul skripsi ini.

Ketiga, angket untuk mendapat data-data yang akurat dari setiap orang tua di jemaat di mana penelitian.

\section{Batasan Penelitian}

Sesuai dengan judul skripsi ini, maka pembahasan hanya sebatas bagaimana orang tua berperanan dalam membentuk spiritualitas anak umur 6-8 tahun di Gereja Kemah Injil Indonesia Jemaat Sei Barang Kalimantan Utara.

\section{Kesimpulan}

Sesuai dengan teori bahwa orang tua harus menjadi figur rohani dalam kehidupan setiap anak, tetapi pada kenyataannya dalam kehidupan sehari-hari bahwa peranan orang tua sebagai figur rohani selama ini terabaikan. Bisa dikatakan bahwa ungkapan yang mengatakan bahwa praktik lebih susah dari teori sepertinya bisa diterapkan dalam kasus ini.

Pertama, orang tua dapat menjalankan peranannya dalam pembentukan spiritualitas anak seperti membawa anak mengenal firman Tuhan atau Alkitab dengan cara memberi pengertian bahwa Alkitab adalah firman Allah yang harus dijadikan sebagai pedoman untuk hidup dalam kebenaran, karena firman Tuhan bermanfaat untuk menyatakan kesalahan, memperbaiki kelakuan dan mendidik untuk hidup dalam kebenaran, serta pelita yang menerangi untuk hidup dalam terang kasih Tuhan.

Kedua, orang tua harus berperan aktif dalam mengajar anak untuk berdoa kepada Tuhan supaya anak dapat menjalin hubungan yang intim dengan Tuhan secara pribadi dengan cara orang tua harus terlebih dahulu tekun dan setia berdoa baik dalam doa secara pribadi maupun dalam doa keluarga agar melalui doa-doa orang tua, anak dapat belajar membangun hubungan dengan Tuhan sehingga spiritualitas atau kedekatan hubungan anak dengan Tuhan akan terbentuk dengan baik.

Ketiga, orang tua harus membawa anak beribadah kepada Tuhan, baik melalui ibadah keluarga dalam rumah tangga maupun melalui kegiatan ibadah yang dilakukan oleh gereja 
seperti kebaktian Sekolah Minggu dengan cara orang tua harus mendorong anak-anaknya pergi ke kebaktian tersebut dan orang tua juga harus membawa anaknya pergi ke gereja untuk beribadah kepada Tuhan setiap hari minggu, supaya anak dapat berbakti untuk bersekutu dengan Tuhan dan melalui persekutuan ibadah tersebut spiritualitas anak akan terbentuk.

Keempat, orang tua harus selalu mengajak anaknya memuji-muji Tuhan dalam ibadah keluarga supaya anak selalu atau senantiasa memuji Tuhan dalam kehidupannya setiap hari, dan melalui kehidupan yang selalu memuji-muji Tuhan, anak dapat belajar tentang kebenaran firman Tuhan dari doktrin yang terkandung dalam lagu-lagu rohani tersebut untuk memuliakan Tuhan dan demi terbentuknya spititualitas anak.

\section{Kepustakaan}

Ali, Mohamad. Metode Penelitian Prosedur Dan Strategi. Bandung: Angkasa, 1985.

Andreas, Subagyo. Pengantar Riset Kuantitatif Dan Kualitatif. Bandung: Yayasan Kalam Hidup, 2004.

Aninda, Ruth Nauli. "Nilai Anak Perempuan pada Keluarga Batak Ditinjau Dari Ibu Dewa sa Awal Dan Dewasa Madya.” Jurnal Ilmiah Mahasiswa Universitas Surabaya 2, no. 1 (Maret 2013): 1-13. Diakses 4 September 2017. http://download.portalgaruda.org/article.php?article=119277\&val=5455.Diaz,

Baucham, Voddie. Gembala-Gembala Keluarga. Bandung: Pioner Jaya, 2012.

Candece, Willan Cackus. Menjadi Orang Tua Yang Berwibawa. Jakarta: Yayasan Pekaba ran Injil Imanuel, 1995.

Daiz, Bartholomeus. "Interpretasi: Dunia Mempertanyakan Apakah Alkitab Bena Diilham kan Allah?” Jurnal Koinonia 9, no. 1 (Mei 2015): 13-21. Diakses 4 Desember 2017. http://jurnal.unai.edu/index.php/koinonia/article/download/183/119.

Desmita. Psikologi Perkembangan Peserta Didik. Bandung: Remaja Rosdakarya, 2017.

Elisabeth. Pendidikan Agama Kristen Pada Anak Usia Dini. Bandung: Bina Media Infor masi, 2009.

Fatimah, Enung. Psikologi Perkembangan. Bandung: Pustaka Setia, 2010.

Gultom, Pujiati. "Prinsip-Prinsip Mengajar Pak Sekolah Minggu Umur 1-12 Tahun.” Jurnal Okrimuniversity 1, no. 1 (April 2010): 1-9. Diakses 29 Juni 2018. http://ejurnal.ukrimuniversity.ac.id/file/P112.pdf.

Gunarsa, Singgi D. Psikologi Perkembangan Anak Dan Remaja. Jakarta: BPK Gunung Mulia, 2017.

Hartono, Handreas. "Membentuk Karakter Kristen Pada Anak Keluarga Kristen.” Jurnal Teologi Dan Pendidikan Agama Kristen 2, no. 1 (Oktober 2014): 62-69. Diakses 12 Mei 2018. http://www.sttpb.ac.id/ejournal/index.php/kurios/article/download/22/23.

Haystead, Wes. Mengajar Anak Tentang Allah. Jakarta: BPK Gunung Mulia, 2001. Horman, Henry Blackaby. Mengalami Doa Bersama Yesus. Jakarta: Metanoa, 2008. Inversen, Rachel. Memulihkan Keluarga. Bandung: Kalam Hidup, 1999. LaHanye, Beverly. Memahami Tamperamen Anak Anda. Bandung: Kalam Hidup, 2002. 
Lester, Andrew. Pelayanan Pastoral Bersama Anak-Anak Dalam Krisis. Malang: Seminari Alkitab Asia Tenggara, 2003.

Leteng, Humbertus. Spiritualitas Imamat Motor Kehidupan Iman. Surabaya: Ladelero, 2003.

Maruanaya, Vita, DAN Weismann, Ivan. "Peran Orang Tua Terhadap Perkembangan

Pribadi Remaja Atas Pemanfaatan Internet di Kalangan Remaja di SMU Advent

Moelung, Lixi J. Metode Penelitian Kuantitatif. Bandung: Rosdakarya, 2010.

Monks, Knoers, Siti Rahayu Haditono. Psikologi Perkembangan, Yogyakarta: Gadjah Mada University Press, 1991.

Munreo, Myles dan David Burows. Kingdom Parenting. Jakarta: Imanuel, 2002.

Nainggolan, John. Menjadi Guru Agama Kristen. Bandung: Bina Media Informasi, 2007.

Narramore, Clyde. Mengadakan Renungan Keluarga. Bandung: Yayasan Kalam Hidup, 2003.

Nazir, Moh. Metode Penelitian. Jakarta: Ghalia Indonesia, 1988.

Ndraha, Roswitha dan Julianto Simanjuntak. Tidak Ada Anak Yang Sulit. Yogyakarta: ANDI, 2009.

Ngir, Desefentison. Panduan Lengkap Sakramen Upacara Gerejawi. Bandung: Kalam Hidup, 2013.

Norman, Wright dan Gary Oliver. Mengoptimalkan Pertumbuhan Karakter Anak Sesuai Dengan Keunikan Pribadinya. Yogyakarta: Gloria Usaha Mulia, 2003.

Nuhamara, Daniel. Bimbingan Pendidikan Agama Kristen. Bandung: Jurnal Informasi Madia 2007.

Nurishan, Juntika, Nubiar Agustin. Dinamika Perkembangan Anak Dan Remaja. Bandung: Refika Aditama, 2011.

Osborne, Rick. Mengajar Anak Anda Berdoa. Bandung: Yayasan Kalam Hidup, 2001.

Penjaitan, Fermin. Pelayanan Pribadi Praktis. Malang: Yayasan Pekabaran Injil Indonesia, 1985.

Sabdono, Erastus. Doa Bapa Kami Permulaan Kehidupan Orang Percaya. Jakarta: Rehobot Literature, 2014.

Setiawani, Mary Go. Menerobos Dunia Anak. Bandung: Yayasan Kalam Hidup, 2004.

Sijabat, Samuel. Strategi Pendidikan Kristen. Yogyakarta: Yayasan ANDI, 1999

Simanjuntak, Julianto dan Roswitha. Mendidik Anak Sesuai Zaman Dan Kemampuannya. Tangerang: Layanan Konseling Keluarga Dan Karir, 2007.

Singgarimbun, Masri dan Sofian. Metode Penelitian Survey. Jakarta: Lembaga Penelitian, 1989.

Syambudin, Abin Maknum. Psikologi Kependidikan. Bandung: Remaja Rordakarya, 2007.

Tabroni. Memperbincangkan Pemikiran Pendidikan. Jakarta: Prenadamedia Group, 2018.

Taylor, Kinneth. Mari Kita Berbakti. Surabaya: Ching Nien, 1986.

Thompson, Marjorie L. Keluarga Pusat Pembentukan Rohani. Jakarta: BPK Gunung Mulia, 2011.

Wade, Carole dan Calor Tavris. Psikologi. Jakarta: Penerbit Erlangga, 2000.

Makassar" Jurnal Jaffray [Online], Volume 8 Nomor 1 (1 April 2010). 
Wadi, Elsyana, DAN Selfina, Elisabet. "Peran Orang Tua Sebagai Keluarga Cyber Smart Dalam Mengajarkan Pendidikan Kristen Pada Remaja GKII Ebenhaezer Sentani Jayapura Papua" Jurnal Jaffray [Online], Volume 14 Nomor 1 (14 Maret 2016).

Waterink. Dengan Bimbingan Ibu. Jakarta: Gunung Mulia, 1980.

Wijanarko, Jarot. Mezbah Keluarga. Jakarta: Suara pemulihan, 2012.

Wijaya, Hengki (ed.). Metodologi Penelitian Pendidikan Teologi. Makassar: Sekolah Tinggi Theologia Jaffray, 2016.

Wommack, Andrew. Kuasa Puji-Pujian. England: Light Publishing, 2002.

Yorkay, Mike Ester, Anggidjaja, dan Lily Cristianto. Ingin Anak Anda Unggul. Jakarta: Departemen Penerbit I.H.O, 1997.

Yulia, Gunarsa Singgih. Asas-Asas Psikologi. Jakarta: BPK Gunung Mulia, 2000.

Yusuf, Syamsu. Psikologi Perkembangan Anak Dan Remaja. Bandung: Remaja Rosdakarya, 2016. 